\title{
Structure Determination of Sucrose by Acetylation and Acid Hydrolysis ${ }^{1}$
}

\author{
Hee-Jeong $\mathrm{Min}^{2} \cdot$ Tae-Seong Lee ${ }^{3} \cdot$ Young-Soo $\mathrm{Bae}^{2 \dagger}$
}

\begin{abstract}
For the structure determination of D-(+)-sucrose, which consists of $\alpha$-D-(+)-glucose and $\beta$-D-(+)-fructose, it was acetylated with acetic anhydride and triethyl amine, pyridine, zinc chloride, and sodium acetate as catalysts. The acetylated D-(+)-sucrose was acid-hydrolyzed using sulfuric acid and sodium chloride in methanolic solution. The structures of the reaction products were determined by ${ }^{1} \mathrm{H}-\mathrm{NMR}$ and ${ }^{13} \mathrm{C}-\mathrm{NMR}$ spectra. The yield of the acetylation indicated the high value in zinc chloride as $70 \%$ in zinc chloride catalyst. The acid-hydrolyzed product of the acetylated D- $(+)$-sucrose, 2,3,4,6,1',3',4',6'-octa-O-acetyl-D-(+)-sucrose, gave 2,3,4,6-tetra-O-acetyl- $\beta$-D-(+)-glucose and it suggests that the acetylated D-(+)-sucrose was rearranged through the formation of oxonium ion by mutarotation in the 2,3,4,6-tetra-O-acetyl$\alpha$-D-(+)-glucose moiety and through the ring opening in the $1^{\prime}, 3^{\prime}, 4^{\prime}, 6^{\prime}$-tetra-O-acetyl- $\beta$-D-(+)-fructose moiety.
\end{abstract}

Keywords : Carbohydrate, Structure determination, Sucrose, Acetylation, Acid hydrolysis

\section{INTRODUCTION}

Carbohydrates are organic compounds which are composed of carbon, oxygen and hydrogen, and are biosynthesized by photosynthesis in plants, including tree species. Especially most of chemical constituents of tree species are carbohydrates, except for lignin and aromatic compounds. In addition to the water soluble polysaccharides, celluloses are entirely composed of $\beta$-D-(+)-glucose and hemicelluloses are complexes which are combined with glucose, mannose and galactose as a hexose monomer and arabinose, xylose and fructose as a pentose monomer.

However, celluloses have been studied on the structure and the utilization for a long time, but it is very little to study on hemicelluloses and water soluble sugars. The chemical structures of carbohydrates have long been studied in USA, Japan, and European countries, but there have been many difficulties in the structure determination of hemicellulose and water soluble sugars due to the macromolecules and the complexity of constitutional sugars, and there are very little studies on the structure of carbohydrate in do-

1 Received January 27, 2014; accepted March 10, 2014

2 Department of Forest Biomaterials Engineering, College of Forest and Environment Sciences, Kangwon National University, Chuncheon 200-701, Korea

3 Research \& Education Institution of World Organic Agriculture and Fisheries, Samcheok 245-802, Korea

† Corresponding author : Young-Soo Bae (e-mail : bae@kangwon.ac.kr) 

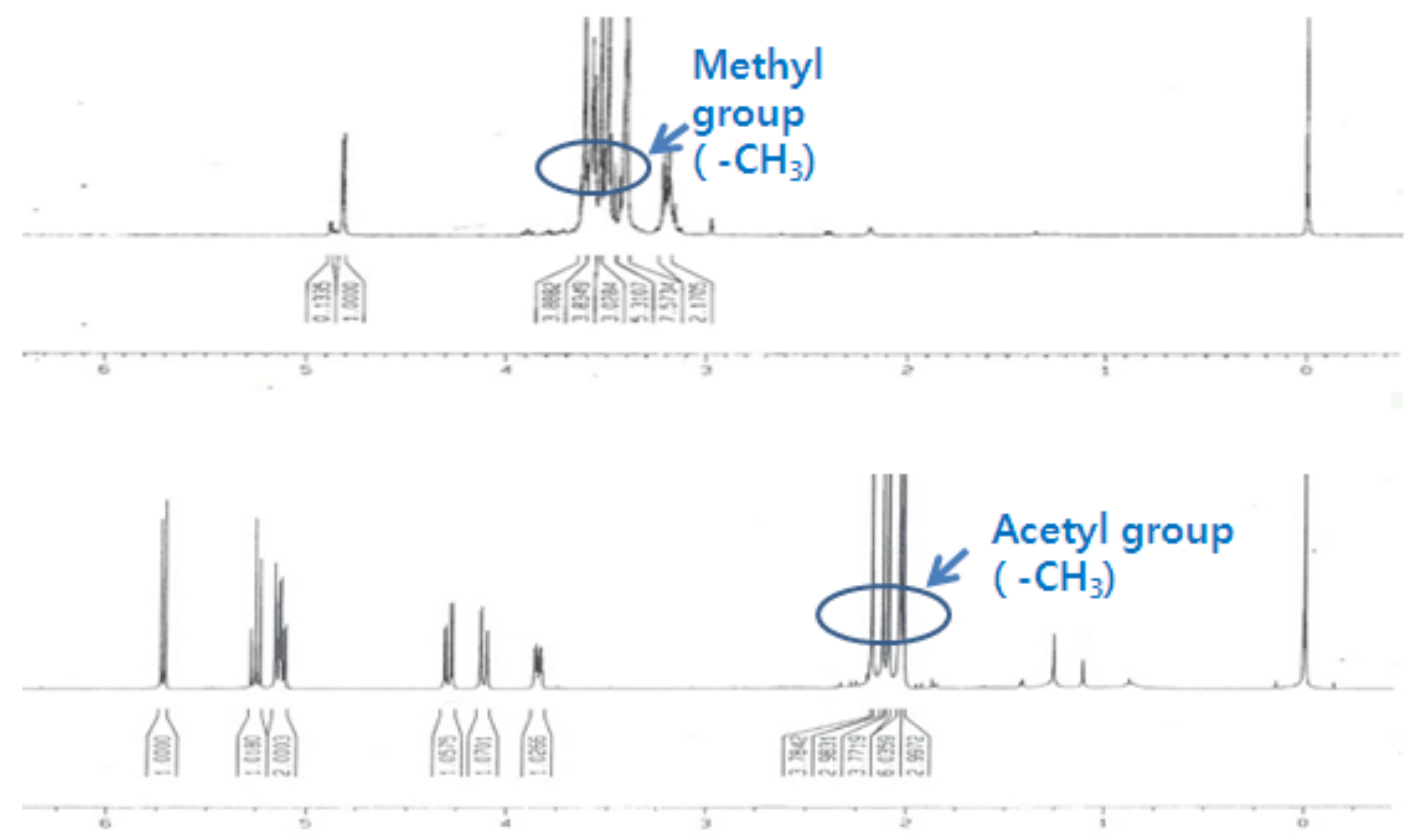

Fig. 1. Comparison of ${ }^{1} \mathrm{H}-\mathrm{NMR}$ spectra of methylated and acetylated carbohydrates.

mestic (Ma Y. 2011).

A disaccharide which two monomeric sugar units are combined together by dehydration reaction is acid hydrolysable. One of the most abundant disaccharides in nature is sucrose which composes the fruit sugar among the water soluble sugars of plants and tree species. It is connected to 1,2-glycosidic linkage and one of major components of sugar cane and sugar beet.

1D-NMR, ${ }^{1} \mathrm{H}-\mathrm{NMR}$ and ${ }^{13} \mathrm{C}-\mathrm{NMR}$, and 2DNMR, COSY and HSQC, are power tools for the study of carbohydrate structure that can be used to determine the skeleton of sugar molecules and to identify carbons and hydrogens in any special position. In the structural study of carbohydrates, the derivatization such as methylation and acetylation on the hydroxyl groups of carbohydrates is widely used to identify the bonding position of sugars and the presence of the substituents in the main chain.

In the methylated sugars, the proton signals of the methyl groups are shown at $\delta \quad 3 \sim 4$ in the ${ }^{1} \mathrm{H}-\mathrm{NMR}$ spectrum and overlapped with the proton signals of the sugar moiety. This means that there can be any troubles in the analysis of the ${ }^{1} \mathrm{H}-\mathrm{NMR}$ signals of a sugar moiety. However, the proton signals of the acetyl groups are shown at $\delta \quad 2 \sim 3$ in the ${ }^{1} \mathrm{H}-\mathrm{NMR}$ spectrum in the acetylated sugar and do not overlapped with those of sugar moiety and acetylation is useful in the structure analysis of sugar (Fig. 1).

D-(+)-sucrose was acetylated, acid hydrolyzed, and then analyzed by NMR spectroscopy to get the basic information for the structure analysis of carbohydrates. 


\section{MATERIALS AND METHODS}

\subsection{Experimental Materials}

D-(+)-sucrose (25 g, Wako, GR) and acetic anhydride (Daejung, $1 \mathrm{~kg}$, GR) were used for the acetylation in this experiment. Triethylamine (Daejung, $1 \mathrm{~kg}, \mathrm{EP}$ ), pyridine (Daejung, $1 \mathrm{~kg}$, $\mathrm{EP}$ ), zinc chloride (Daejung, $1 \mathrm{~kg}, \mathrm{EP}$ ) and sodium acetate (Daejung, $1 \mathrm{~kg}, \mathrm{EP}$ ) were also used as catalysts to get the acetylated D-(+)-sucrose. Methylene chloride (Daejung, 4 L, GR), sodium bicarbonate (Daejung, $1 \mathrm{~kg}$, GR), sodium sulfate (Wako, $1 \mathrm{~kg}, \mathrm{GR}$ ) and $6 \mathrm{M}$ hydrogen chloride (Wako, $500 \mathrm{ml}$, GR) were used to purified the acetylated D-(+)-sucrose. 98\% of sulfuric acid (Wako, $500 \mathrm{ml}$, GR) and $\mathrm{NaCl}$ were applied to the methanolic acetylated $\mathrm{D}-(+)$-sucrose solution to get the hydrolyzed $\mathrm{D}-(+)$-sucrose products.

\subsection{Acetylation}

\subsubsection{Acetylation with Triethylamine and Pyridine}

Acetic anhydride $(7 \mathrm{ml})$ and pyridine (or triethylamine) $(20 \mathrm{ml})$ were combined together and cooled to $0^{\circ} \mathrm{C}$, and $\mathrm{D}-(+)$-sucrose $\left.0.5 \mathrm{~g}\right)$ was added into the solution. The suspension was stirred at $0^{\circ} \mathrm{C}$ until the sugar is all dissolved. The solution is allowed to stand $18 \mathrm{hr}$. at room temperature and was then poured with stirring into $20 \mathrm{ml}$ of ice water. The reaction mixture was filtered with suction, washed with cold water, and then dried at room temperature (Peter M. 1995).

\subsubsection{Acetylation with Sodium Acetate An- hydrous}

The suspension of anhydrous sodium acetate $(2 \mathrm{~g})$ and acetic anhydride $(15 \mathrm{ml})$ in a round- bottomed flask was heated to the boiling point in an efficient fume hood. Then D-(+)-sucrose (1 g) was added into the flask. Initiation of the reaction was indicated by the continuous boiling even after the stopping of the heating ; the flask was placed on a cork ring, and the heating was extinguished. After the reaction was subsided, the solution was brought to a full boil. It was then cooled and poured into $20 \mathrm{ml}$ of ice water. After standing $3 \mathrm{hr}$. with stirring at room temperature, the reaction product was filtered with suction, washed with cold water, and then dried (Peter M. 1995).

\subsubsection{Acetylation with Zinc Chloride}

D-(+)-sucrose $(0.5 \mathrm{~g})$ was added to the solution of zinc chloride (3.3 g) and acetic anhydride $(10 \mathrm{ml})$ at $0^{\circ} \mathrm{C}$, then the mixture was stirred vigorously until the sugar was all dissolved for about $4 \sim 5 \mathrm{hrs}$. The temperature was kept at $20 \sim 25^{\circ} \mathrm{C}$ for $1 \mathrm{hr}$ and then at $50^{\circ} \mathrm{C}$ for $2 \mathrm{hrs}$. The cooled solution was stirred for $2 \mathrm{hr}$. with $20 \mathrm{ml}$ of ice water and then neutralized with an excess amount of sodium hydrogen carbonate. The mixture was extracted with $15 \mathrm{ml}$, of chloroform; the chloroform solution is washed with water, dried with anhydrous sodium sulfate, and evaporated under the reduced pressure to get a syrup, compound 2, to be freeze dried (Peter M. 1995).

\subsection{Acid Hydrolysis}

The acetylated sucrose $(0.5 \mathrm{~g})$ and $20 \mathrm{ml}$ of methanol were completely dissolved in a roundbottomed flask at room temperature. Some amount of $98 \%$ sulfuric acid was poured in a separatory pressure dropping funnel, some of $\mathrm{NaCl}$ powder was poured in a round-bottom flask, and then 
two devices were connected together. One end of a tube was connected to the funnel outlet and the other end was connected to a glass pipet to be dipped into the methanolic acetylated sucrose solution. Then sulfuric acid was slowly fell in 4 $\sim 5$ drops over $\mathrm{NaCl}$ powder to creat $\mathrm{HCl}$ gas to be injected into the methanolic solution for 5 min. The flask was sealed, stirred to get the acid-hydrolyzed product, compound 3, for 24 hrs, and then evaporated to be freeze dried.

\subsection{Structure Determination of the Reac- tion Products}

${ }^{1} \mathrm{H}$ - and ${ }^{13} \mathrm{C}$-NMR spectra were recorded on a Bruker Avance DPX $400 \mathrm{MHz}$ spectrometer using tetramethylsilane (TMS) as an internal standard and chemical shifts are given in $\delta$ (ppm). NMR solvents were DMSO, $\mathrm{D}_{2} \mathrm{O}$ and $\mathrm{CDCl}_{3}$.

\subsubsection{Compound 1 (D-(+)-sucrose)}

${ }^{1}$ H-NMR(400 MHz, $\left.\delta, \mathbf{C D C l}_{3}\right): 3.47(1 \mathrm{H}, \mathrm{t}$, H-4), 3.56 (1H, t, H-2), 3.68 (2H, t, H-1'), 3.76 $(1 \mathrm{H}, \mathrm{t}, \mathrm{H}-3), 3.81(2 \mathrm{H}, \mathrm{m}, \mathrm{H}-6), 3.82(2 \mathrm{H}, \mathrm{m}$, H-6'), 3.86 (1H, m, H-5), 3.89 (1H, t, H-5'), $4.06\left(1 \mathrm{H}, \mathrm{t}, \mathrm{H}-4^{\prime}\right), 4.22\left(1 \mathrm{H}, \mathrm{t}, \mathrm{H}-3^{\prime}\right), 5.42(1 \mathrm{H}$, $\mathrm{d}, \mathrm{J}=3.53 \mathrm{~Hz}, \mathrm{H}-1)$.

${ }^{13} \mathrm{C}-\mathrm{NMR}\left(100 \mathrm{MHz}, \delta, \mathbf{C D C l}_{3}\right): 60.93$ (C-6), 62.48 (C-1'), 62.60 (C-6'), 70.28 (C-4), 72.09 (C-2), 73.28 (C-5), 73.31 (C-3), 74.72 (C-4'), 77.44 (C-3'), 83.02 (C-5'), 92.20 (C-1), 104.492 (C-2')

\subsubsection{Compound 2 (acetylated D-(+)-su- crose)}

${ }^{1}$ H-NMR (400 MHz, $\delta, \mathbf{C D C l}_{3}$ ) : 2.02 2.12 (24H, m, H-acetyl) $4.16\left(2 \mathrm{H}, \mathrm{m}, \mathrm{H}-1^{\prime}\right), 4.17$ (2H, m, H-6), 4.22 (1H, m, H-5'), 4.30 (1H, m, H-5), 4.33 (2H, m, H-6'), 4.87 (1H, dd, J=3.6Hz and $\mathrm{J}=3.81 \mathrm{~Hz}, \mathrm{H}-2), 5.08(1 \mathrm{H}, \mathrm{t}, \mathrm{H}-4), 5.37$, $(1 \mathrm{H}, \mathrm{t}, \mathrm{H}-4), 5.44(1 \mathrm{H}, \mathrm{t}, \mathrm{H}-3), 5.45(1 \mathrm{H}, \mathrm{d}$, $\left.\mathrm{J}=4.4 \mathrm{~Hz}, \mathrm{H}-3^{\prime}\right), 5.69(1 \mathrm{H}, \mathrm{d}, \mathrm{J}=3.69 \mathrm{~Hz}, \mathrm{H}-1)$.

${ }^{13} \mathbf{C}-\mathbf{N M R}\left(100 \mathrm{MHz}, \quad \delta, \quad \mathbf{C D C l}_{3}\right) \quad: \quad 20.60$ (acetyl $\mathrm{CH}_{3}$ ), 61.86 (C-1'), 63.00 (C-6), 63.71 (C-6'), 68.40 (C-4), 68.62 (C-5), 69.76 (C-3'), 70.40 (C-2), 75.16 (C-4'), 75.87 (C-3), 79.23 (C-5'), 90.08 (C-1), 104.09 (C-2'), 167.47 169.98 (acetyl $\mathrm{C}=\mathrm{O}$ ).

\subsubsection{Compound 3 (acetylated $\beta-\mathrm{D}-(+)$ glucopyranose)}

${ }^{1}$ H-NMR(400 $\left.\mathbf{~ M H z , ~} \delta, \mathbf{C D C l}_{3}\right):$ : 2.01 2.12 (16H, m, H-acetyl), 3.85 (1H, m, H-5), 4.12 $(1 \mathrm{H}, \mathrm{dd}, \mathrm{J}=2.13 \mathrm{~Hz}$ and $\mathrm{J}=2.14 \mathrm{~Hz}, \mathrm{H}-6), 4.29$ $(1 \mathrm{H}, \mathrm{dd}, \mathrm{J}=4.52 \mathrm{~Hz}$ and $\mathrm{J}=4.52 \mathrm{~Hz}, \mathrm{H}-6), 5.12$ $(1 \mathrm{H}, \mathrm{dd}, \mathrm{J}=3.69 \mathrm{~Hz}$ and $\mathrm{J}=3.74, \mathrm{H}-3), 5.15(1 \mathrm{H}$, $\mathrm{dd}, \mathrm{J}=2.33 \mathrm{~Hz}$ and $\mathrm{J}=2.71 \mathrm{~Hz}, \mathrm{H}-2), 5.26(1 \mathrm{H}, \mathrm{t}$, $\mathrm{H}-4), 5.72$ (1H, d, J=8.16Hz, H-1).

${ }^{13} \mathbf{C}-\mathrm{NMR}\left(100 \mathrm{MHz}, \quad \delta, \quad \mathbf{C D C l}_{3}\right) \quad: \quad 20.60$ (acetyl $\mathrm{CH}_{3}$ ), 61.85 (C-6), 68.14 (C-4), 70.62 (C-5), 73.11 (C-2), 75.19 (C-3), 90.08 (C-1), 170.06 170.64 (acetyl $\mathrm{C}=\mathrm{O}$ ).

\section{RESULTS AND DISCUSSION}

D-(+)-sucrose (compound 1) was acetylated by triethylamine, pyridine, sodium acetate anhydrous, and zinc chloride as catalysts. The acetylated D-(+)-sucrose (compound 2) was treated using sulfuric acid and $\mathrm{NaCl}$ to get the acid-hydrolyzed product and gave the compound $\mathbf{3}$, 2,3,4,6-tetra-O-acetyl- $\beta$-D-(+)-glucopyranose (Fig. 3).

In the ${ }^{1} \mathrm{H}-\mathrm{NMR}$ spectrum, $\mathrm{H}-1$ gave a doublet at $\delta \quad 5.42$ and the coupling constant was 3.52 $\mathrm{Hz}$ indicating $\alpha$-D-(+)-glucose. H-2, H-3 and H-4 indicated triplet signals at $\delta 3.56, \delta 3.76$, and $\delta$ 3.47, respectively. H-5 and H-6 showed 


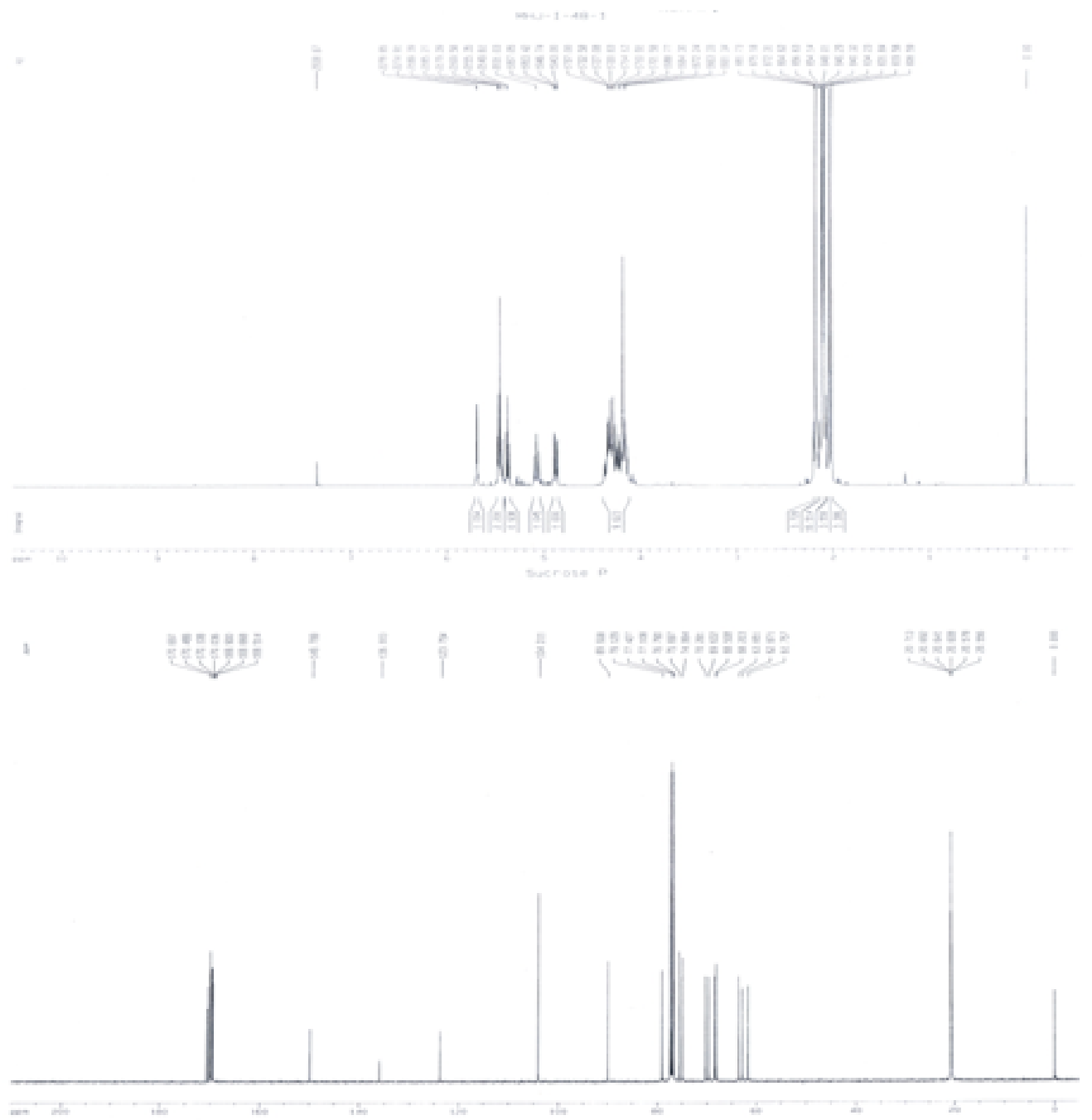

Fig. 2. NMR spectrum of Acetylated D-(+)-sucrose.

two multiplet signals at $\delta 3.86$ and $\delta 3.81$, respectively. $\mathrm{H}-\mathrm{1}^{\prime}$ of the $\beta$-D-(+)-fructose moiety gave a triplet at $\delta$ 3.68. $\mathrm{H}-3^{\prime}, \mathrm{H}-4^{\prime}$ and $\mathrm{H}^{\prime}-5$ also gave three triplets at $\delta 4.22, \delta 4.06$ and $\delta 3.89$, respectively. Two protons of $\mathrm{H}-6^{\prime}$ showed a multiplet signal at $\delta$ 3.82. In the ${ }^{13} \mathrm{C}-\mathrm{NMR}$ spectrum, $\mathrm{C}-1$ of the $\alpha$-D-(+)-glucose moiety gave a signal at $\delta$ 92.90. C-2, C-3, C-4 and $\mathrm{C}-5$ indicated the signals at $\delta 72.09, \delta$
73.31, $\delta 70.28$ and $\delta 73.28$, respectively. C-6 gave a most-upfielded signal at $\delta$ 60.93. $\mathrm{C}-1^{\prime}$ of the $\beta$-D-(+)-fructose moiety gave a signal at $\delta$ 62.48. C-2', C-3' and C-4' indicated signals at $\delta 72.09, \delta 77.44$ and $\delta 74.72$, respectively. C-'5 gave a downfielded signal at $\delta 83.02$ in the spectrum. C- 6 ' showed a signal at $\delta 62.60$. These NMR data were identical to the literature (Mehta B.K. 2008). 

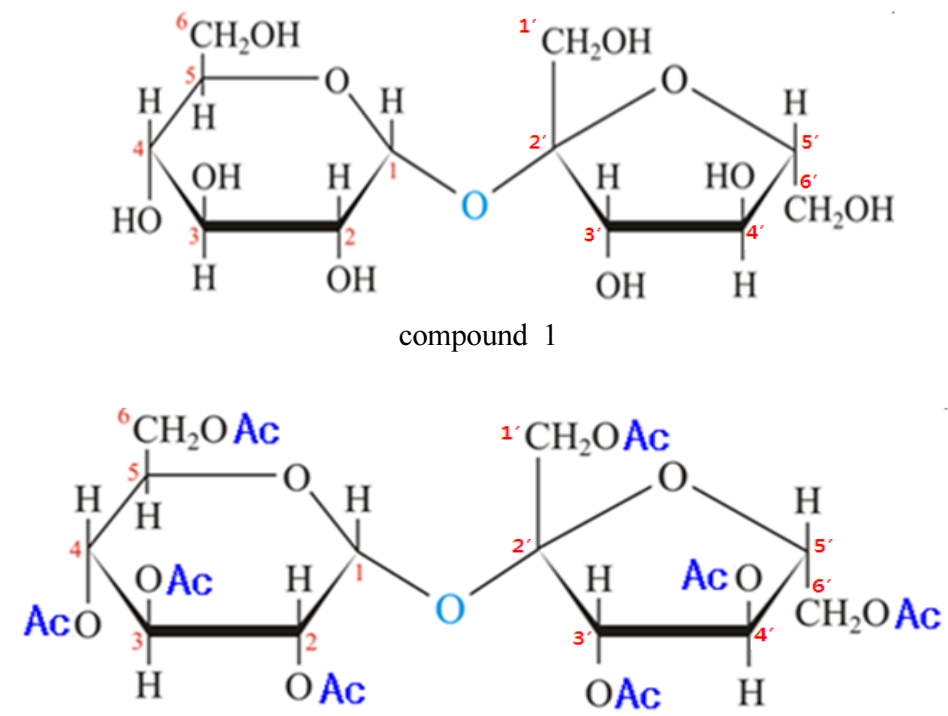

compound 2

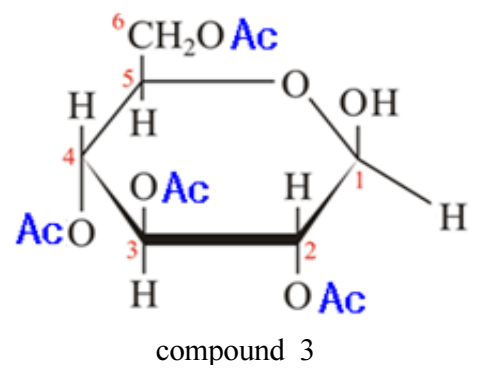

Fig. 3. Chemical structures of the compound 1 3.

Compound 2 gave free dried dark brown powder. In the ${ }^{1} \mathrm{H}-\mathrm{NMR}$ of compound $\mathbf{2}$ (Fig. 2), H-1 of the glucose moiety showed a doublet at $\delta 5.69$ with the coupling constant of 3.69 $\mathrm{Hz}$ indicating a-anomer. $\mathrm{H}-2$ gave a double doublet signal at $\delta$ 4.87. $\mathrm{H}-3$ and $\mathrm{H}-4$ were resonated at $\delta 5.44$ and $\delta 5.08$, respectively, with two triplet signals. H-5 and H-6 gave two multiplets at $\delta 4.30$ and $\delta 4.17$, respectively. $\mathrm{H}-1^{\prime}$ of the fructose moiety gave a multiplet at $\delta$ 4.16. H-3' and H-4' showed a doublet and a triplet signals at $\delta 5.45$ and $\delta 5.37$, respec- tively. $\mathrm{H}-5^{\prime}$ and $\mathrm{H}-6$ ' indicated two multiplets at $\delta 4.22$ and $\delta 4.33$, respectively. In the ${ }^{1} \mathrm{H}-\mathrm{NMR}$ of compound 2 , the chemical shifts of most protons were downfield shifted about $0.5 \sim 1 \mathrm{ppm}$ compare to the compound $\mathbf{1}$ due to the conjugation effect from the substituted acetyl groups. The methyl protons of the acetyl groups gave eight signals at $\delta$ 2.02 2.12. These ${ }^{1} \mathrm{H}-\mathrm{NMR}$ signals were similar to those of the literature (Chandrika B. 2005).

In the ${ }^{13} \mathrm{C}-\mathrm{NMR}$ spectrum (Fig. 2), $\mathrm{C}-1$ of the glucose moiety showed a signal at $\delta$ 90.08. 

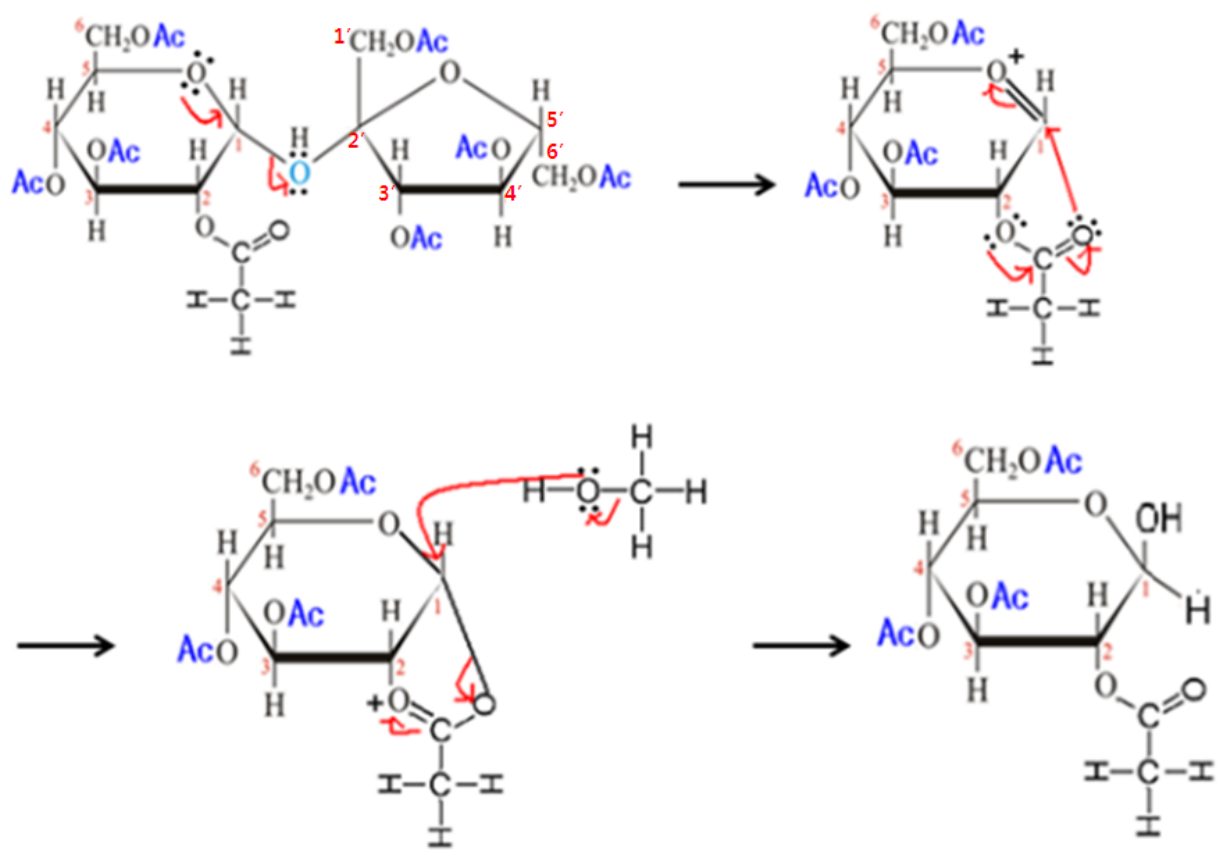

Fig. 4. Rearrangement of the acetylated $\alpha$-D-(+)-glucose through the formation of oxonium ion.

$\mathrm{C}-2$ and $\mathrm{C}-3$ gave signals at $\delta 70.4$ and $\delta$ 75.87, respectively. Also C-4 and C-5 resonated at $\delta 68.40$ and $\delta 68.62$, respectively. C-6 gave a signal at $\delta$ 63.0. $\mathrm{C}-1^{\prime}$ of the fructose moiety gave a signal at $\delta \quad 61.86$ and C-2' showed a signal at $\delta 104.09$ which was downfield shifted about $30 \mathrm{ppm}$ compare to the signal of compound 2. It may be the conjugation effect from the substituted acetyl group. C-3' and C-4' gave signals at $\delta 77.44$ and $\delta 74.72$, respectively. Also C-5' and C-6' indicated signals at $\delta 83.02$ and $\delta 62.60$, respectively. The carbonyls of the acetyl group gave eight signals at $\delta$ 167.47 169.98 and the methyls of the acetyl groups indicated the signals at $\delta \quad 20.60 \sim 20.80$. These NMR data were identical to the acetylated D-(+)-sucrose, 2,3,4,6,1',3',4',6'-octa-O-acetyl-D(+)-sucrose (Jung M.H. 2004.).

Compound 3 was freeze dried to dark brown powder. In the ${ }^{1} \mathrm{H}-\mathrm{NMR}$ spectrum, the four methyl protons from acetyl groups gave the multiple signals at $\delta 2.02 \sim 2.12$. H-1 gave the doublet signals at $\delta 5.72$ and the coupling constant was $8.16 \mathrm{~Hz}$ indicating the structure of $\beta$ -D-(+)-glucopyranose. H-2 and H-3 showed double doublet signals at $\delta 5.15$ and $\delta 5.12$, respectively. $\mathrm{H}-4$ indicated a triplet signal at $\delta$ 5.26 and $\mathrm{H}-5$ gave a multiplet signal at $\delta 3.85$. Two protons of H-6 showed two double doublet signals at $\delta 4.12$ and $\delta 4.29$. According to the above ${ }^{1} \mathrm{H}-\mathrm{NMR}$ data, compound $\mathbf{3}$ was identical to tetra-O-acetyl- $\beta$-D-(+)-glucopyranose and to the known data (Ma Y., 2001; Yang Z., 2000). In the ${ }^{13} \mathrm{C}-\mathrm{NMR}$ spectrum, four carbonyl carbons of the acetyl groups gave the four signals at $\delta 170.06 \sim 170.64$. Four methyl carbons of the acetyl groups also indicated the signals at $\delta$ 20.4 20.6. C-1 gave a signal at 90.8 indica- 


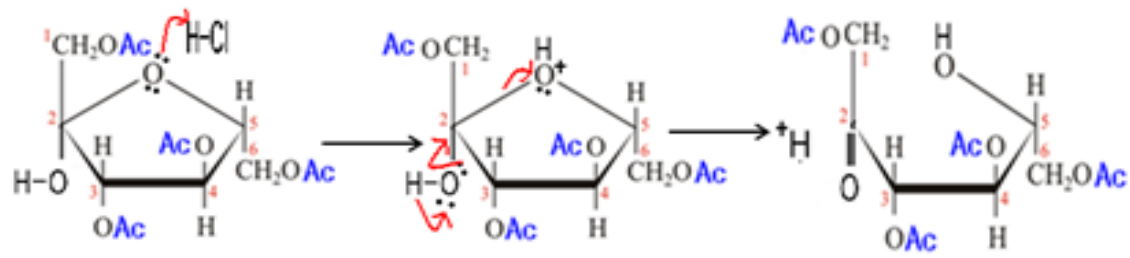<smiles>COCC(O)C(OC)C(C)C(=O)COC(C)=O</smiles>

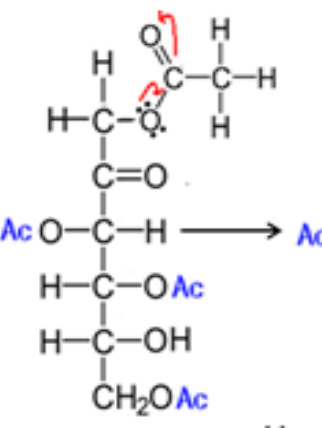

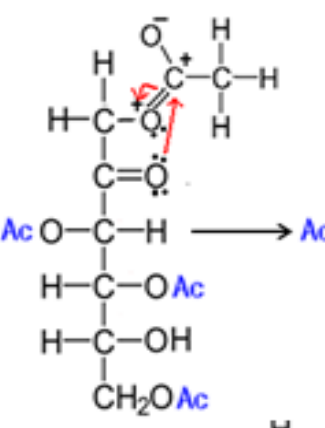

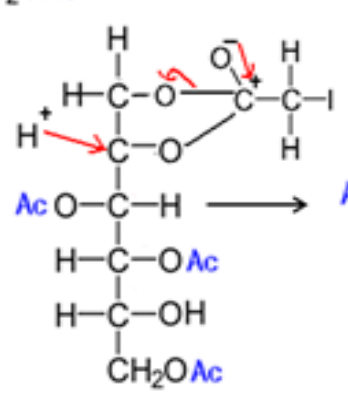

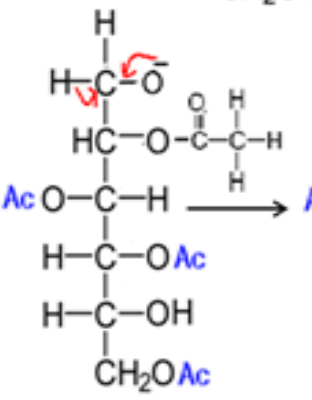<smiles>COCC(O)C(OC)C(OC)C(C)OC=O</smiles>

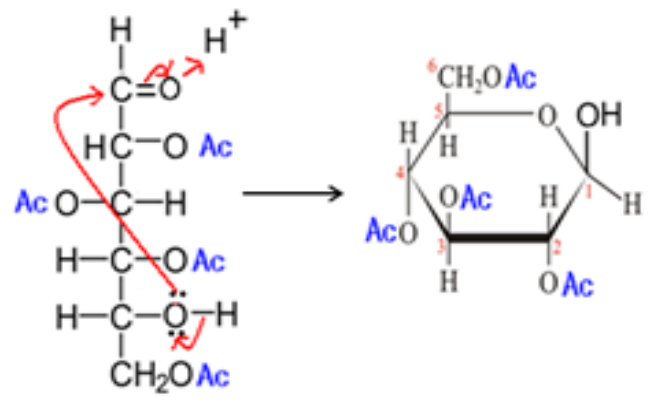

Fig. 5. Rearrangement of the acetylated $\beta-\mathrm{D}-(+)$-fructose through ring opening.

ting $\beta$-D-(+)-glucose and $\mathrm{C}-2$ and $\mathrm{C}-3$ were shown the signals at $\delta 73.11$ and $\delta 75.19$, respectively. The other C-4, C-5 and C-6 indicated the signals at $\delta 68.14, \delta 70.62$, and $\delta$ 61.85, respectively. The above ${ }^{1} \mathrm{H}$ - and ${ }^{13} \mathrm{C}$ NMR data were identical to 2,3,4,6-tetra-O-ace- tyl- $\beta$-D-(+)-glucopyranose (Ma Y., 2001; Yang Z., 2000).

The formation of 2,3,4,6-tetra-O-acetyl- $\beta$-D(+)-glucopyranose acid hydrolysis of the acetylated $\mathrm{D}$-(+)-sucrose suggests that 2,3,4,6-tetra-O-acetyl- $\alpha$-D-(+)-glucopyranose moiety of 
the acetylated $\mathrm{D}-(+)$-sucrose was rearranged through the formation of oxonium ion by mutarotation (Fig. 4) $\left(8,10\right.$, ) and that $1^{\prime}, 3^{\prime}, 4^{\prime}, 6^{\prime}$-tetra-O-acetyl- $\beta$-D-(+)-fructose moiety was also rearranged after the ring opening (Fig. 5) (Hassan S., 1998; Jone F., 1998; Sokolov V.M., 2002.).

The acetylation yield of D-(+)-sucrose by catalysts indicated the highest as $69 \%$ in $\mathrm{ZnCl}_{2}$, $51 \%$ in pyridine, and $49 \%$ in both of triethylamine and sodium acetate. However, these yields may be changed according to molecular sizes of carbohydrates.

\section{CONCLUSION}

D-(+)-sucrose, a disaccharide, was acetylated with acetic anhydride, and triethylamine, pyridine, sodium acetate anhydrous and zinc chloride as reaction catalysts. Then the acetylated D-(+)-sucrose was acid hydrolyzed by $\mathrm{HCl}$ gas from $98 \%$ sulfuric acid and $\mathrm{NaCl}$ to give the hydrolyzed product, 2,3,4,6-tetra-O-acetyl- $\beta$ D-(+)-glucopyranose.

The formation of 2,3,4,6-tetra-O-acetyl- $\beta$ D-(+)-glucopyranose from the acetylated D$(+)$-sucrose by acid hydrolysis means that 2,3 , 4,6-tetra-O-acetyl- $\alpha$-D-(+)-glucose moiety of the acetylated $\mathrm{D}-(+)$-sucrose was rearranged through the formation of oxonium ion and that 1',3',4',6'-tetra-O-acetyl- $\beta$-D-(+)-fructose moiety was also rearranged after the ring opening.

In the catalystic reaction of $\mathrm{D}$-(+)-sucrose, $\mathrm{ZnCl}_{2}$ was more effective as the yield of $69 \%$ and the rests were around $50 \%$. However, the catalystic yield can be different from the kind of carbohydrate and will need further study in the future.

\section{ACKNOWLEDGEMENT}

This work was supported by the Basic Research Program for Forest Science of Korean Forest Service (No S211313L010130) and also partially by 2013 Research Grant from Kangwon National University (No 120131803).

\section{RREFERENCES}

1. Alexander, M., C. Edilson, and O. Clarissa. 2006. A theoretical study of glucose mutarotation in aqueous solution. Carbohydrate research. 341(8): 1029 1040 .

2. Baby Chandrika and Laura K. 2005. Schnackenberg, Poovathinthodiyil Raveendran, and Scott L. Wallen. High Resolution ${ }^{1} \mathrm{H}$ NMR Structural Studies of Sucrose Octaacetate in Supercritical Carbon Dioxide. Chemistry A European Journal. 11: 6266 6271.

3. Hassan, S. and El Khadem. 1998. Carbohydrate chemistry, Monosaccarides and their oligomers. $101 \sim 102$.

4. Jone F. Kennedy. 1998. Research Laboratory for the Chemistry of Bioactive Carbohydrates and Proteins, Department of Chemistry, University of Birmingham, Birmingham, UK and North-East Wales Institute, Clwyd, UK. Carbohydrate chemistry. 12.

5. Jone McMurry. 2008. Organic chemistry. 944.

6. Jung, M.-H., H.-S. Kim, S.-D. Ahn, C.-T. Kimb. 2004. Complete Assignment of the ${ }^{1} \mathrm{H}$ and ${ }^{13} \mathrm{C}$ NMR Spectra of a Sucrose Ester from Euphorbia Lathyris L. Journal of the Korean Magnetic Resonance Society 2000(4): $125 \sim 132$.

7. Ma, Y., G. Lian, Y. Li, and B. Yu. 2011. Identification of 3,6-Di-O-acetyl-1,2,4-O-orthoacetyl- $\alpha$-D-glucopyranose as a Direct 
Evidence for the 4-O-Acyl Group Participation in Glycosylation. Royal Society of Chemistry. 47: $7515 \sim 7517$.

8. Mehta, B.K., U. Sharma, S. Agrawal, V. Pandit, N. Joshi, and M. Gupta. 2008. MEDICINAL CHEMISTRY RESEARCH. Isolation and characterization of new compounds from seeds of Nigella sativa : 470 .

9. Park, S.-Y., I.-G. Choi, Y.-S. Bae. 2013. The Structure Determination of the Extractives and A Polysaccharide from Taxus cuspidata fruits. Journal of the Korean Wood Science and Technology. 41(6): 566 575.

10. Peter, M. C. and Ferrier, R. J. 1995. Monosaccharides, Their chemistry and their roles in natural products. $40 \sim 41$.

11. Sokolov, V.M., V.I. Zakharov, and E.P. Studentsov. 2002. Stereoselectivity of Reactions at the Glycoside Center of Carbohydrates: VII. Synthesis of Aryl a- and -b-DGlucopyranosides by Helferich, Catalyzed by Boron Trifluoride Etherate. Russian Journal of General Chemistry. 72(5): 806 3811.

12. Wolfro, M.L. and Thompson, A. 1963. Methods in carbohydrate chemistry. 53: $211 \sim 214$.

13. Yang, Z, W. Lin, B. Yu. 2000. Rearrangement of sugar 1,2-orthoesters to glycosidic products: amechnistic implication. Carbohydrate Research. 329: 879 884. 